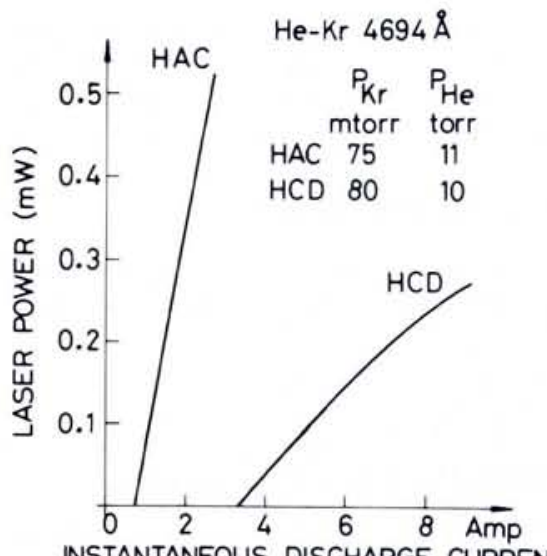

INSTANTANEOUS DISCHARGE CURRENT

Fig. 6 - Dependence of laser power on discharge current in hollow cathode / $\mathrm{HCD} /$ and hollow anode-cathode / HAC/ discharges.

The origin of laser oscillation in HAC discharges with a charge-transfer exited system remained unexplained and experiments have been carried out to determine whether in the relatively large internal diameter $(7 \mathrm{~mm}) \mathrm{HAC}$ discharge tube of a $\mathrm{Ne}-\mathrm{Al}$ laser, a metal vapour density high enough for laser oscillation could build up inside the internal anode structure. Investigations have also been made of other cathode sputtering operated HAC metal vapour lasers, notably the $\mathrm{He}-\mathrm{Cu}$ and $\mathrm{He}$ $\mathrm{Zn}$ systems. In a $\mathrm{He}-\mathrm{Cu}$ laser, $30 \mathrm{~mW}$ infrared laser power output was obtained whereas with a He-Zn HAC laser, a much higher output power is produced by heating than by sputtering.

To summarize, much progress has been made in clarifying hollow cathode tube construction principles and in finding new hollow cathode laser systems, but there are still basic problems waiting to be solved.

\title{
Physics Periodicals in Europe
}

In collaboration with the Publications Committee of the European Physical Society, a meeting was organized by UNESCO in Paris on 25 January 1982 which brought together a broad representation of editors and publishers of physics journals in Europe, with experts from organizations concerned with the publication of learned journals on a wider level. The object of the meeting was to encourage an exchange of views on some of the pertinent questions facing the various sectors of the publication system. Although special attention was given to physics, as was emphasized in the opening address prepared by $A$. Kaddoura (UNESCO Assistant DirectorGeneral for Science), most of the problems current in physics are common to all the disciplines. The subjects covered, were refereeing, the impact of modern technology, marketing and the role of international organizations in the publishing complex.

Within the Publications Committee, discussions had been held on the conflicts inherent in the refereeing system and the abuses that were alleged to exist. In the light of these a set of guide-lines on refereeing had been drawn up for presentation to the meeting by the Secretary, E.N. Shaw. These were aimed essentially at providing a better understanding between authors and publishers (including editors and referees) rather than laying down specific procedures. The key question was whether guide-lines of any sort would serve a useful purpose. It is easy to exaggerate the frequency of refereeing errors and the misuse of information while it is still confidential. In physics especially, the standard of publishing practices is generally high and for the most part a considerable effort is made by editors and referees to upgrade the level of submitted papers so that they can be published.

Whereas there was general approval of most of the "rules" proposed, opinions were divided on their utility and whether they would help in the most difficult cases, notably when the editor (referee) considered the submission to be "irrelevant". The discussion will be continued.

A special plea was made by F. GarciaMoliner from Spain on behalf of the physicists in countries which were not publishers of core journals. One of their major problems was isolation and this was evident in the little representation of physicists from such countries on the Editorial Boards and refereeing lists of journals.

Whilst many publishers are anxious to have a wide geographical spread on their boards there are practical problems of communication. Even if contact can be maintained by mail, transmission is often slow, there is no guarantee in some countries that a document will be received, or that a document returned will not be subject to serious delay. The publisher was under great pressure to publish with maximum speed and this tended to be given priority. Even UNESCO was powerless to intervene in the internal communication practices of any country but this was clearly an area where the EPS and its Divisions could collaborate with publishers and the subject

\section{Individual Members of the European Physical Society approved by Council at the end of 1981}

\section{Category 4A}

M.A. Ahmed, Budapest, $H$

L. Struik, Delft, NL

\section{Category 4C}

Eötvös Lorand Physical Society

J. Bakos, Budapest

J. Gyulai, Budapest

L. Kertesz, Budapest

J. Kojnok, Budapest

D. Marton, Budapest

\section{French Physical Society}

R. Pick, Paris

J. Pirenne, Liège, B

J. Jacquinot, Chatenay-Malabry

J.-L. Leroy, Bagnères-de-Bigorre

F. Touchard, Orsay

\section{German Physical Society}

F.H. Effertz, Köln

R.J. Jelitto, Frankfurt/Main

G. Landwehr, Grenoble, F

W. Ohlendorf, Garching

W. Ruland, Marburg

H. Schmidt, Stuttgar
Finnish Physical Society

S.O. Bäckman, Pargas

P. Eskola, Helsinki

R.G. Gylling, Helsinki

B. Hedkrok, Raums

R. Hämäläinen, Onttola

$\mathrm{H}$. Ihalainen, Tampere

H. Ilomäki, Lohja

J. Joensuu, Helsinki

J. Kantele, Jyväskylä

M. Kara, Helsinki

A.E. Levanto, Oulu

P. Lounesto, Helsinki

J. Maalampi, Helsinki

H. Moilanen, Suolahti

M. Rosenblad, Helsinki

K. Salonen, Turku

R. Simonsson, Espoo

S.E. Stenij, Helsinki

H. Stenlünd, Espoo

J. Teinonen, Helsinki

R. Terho, Raisio

P. Tuomi, Espoo

T. Valkonen, Turku

I. Vallinoja, Helsinki

T. Vehanen, Espoo

J. Virtamo, Espoo
Hellenic Physical Society

E. Anastassakis, Athens

The Institute of Physics

M. Ebison, London

D.J. Munday, Geneva, $\mathrm{CH}$

Italian Physical Society

M. Mazzoni, Florence

L.C. Pucci, Bologna

The Netherlands' Physical Society

E.P.J. van den Heuvel, Amsterdam

C. van Dijk, Bergen-NH

Norwegian Physical Society

J.M. Hansteen, Bergen

T. Jøssang, Oslo

Physical Section, Union of Yugoslav

Societies of Mathematicians, Physi-

cists and Astronomers

M. Dimitrijevic, Belgrade

Portuguese Physical Society

A. Elias, Lisbon
Spanish Royal Society of Physics

A.L. Garrido Simon, Madrid

Swiss Physical Society

W. Däppen, Sauverny

G. Pfister, Männedorf

Turkish Physical Society

H. Akçay, Ankara

Y.C. Akgoz, Ankara

E. Aksahin, Ankara

T. Armagan, Bornova-Izmir

Y. Bektore, Izmir

N. Büget, Ankara

D. Evin, Ankara

T. Firat, Ankara

Y. Güler, Ankara

C. Gumus, Trabzon

H. H. Güven, Istanbul

T. Incesu, Ankara

M.S. Kilickaya, Eskisehir

A. Kolat, Ankara

G. Öke, Ankara

N. Özalp, Trabzon

A.M. Özer, Ankara

M.E. Ozsan, Ankara

R.G. Oraltay, Ankara

G. Tepehan, Istanbul

N. Türetken, Ankara

Y. Tulunay, Ankara

B. Yaramis, Istanbul 
will be taken up by the Publications Committee.

The impact of modern technology was reviewed by $M$. Katzen of the Primary Communications Research Centre, Leicester who made a clear distinction between what was theoretically possible with electronically based information processing, and what was either economic or desirable. Although theoretically a continuous conference of authors and readers is possible, the computer power needed is very large, the TV screen is not the most suitable presentation for reading anything but bare data, and the management of information processes demands continuous intellectual effort. Nevertheless, there was little doubt that electronic techniques would have - indeed were already having - an important impact on traditional practices. Examples cited were: simplifying the input of information into the publisher, speeding through word processors communication between authors, editors and referees and giving the opportunity for interactive exchanges, and then direct transmission to the storage medium. In addition, office procedures were being streamlined and the publisher was able to offer more custom-built packaging of information - and handle the associated billing, an aspect often forgotten by scientists.

Reference data bases were already established and full-text data bases were being actively developed. Nevertheless these should be seen as an additional primary product source rather than a complete substitute for the printed word. A considerable effort was being put into the creation of communication networks able to handle voluminous material (including formulae and graphics) and devising methods for entering data as directly as possible into the bases. Opinions varied on the rapidity with which problems of standardisation and the very complex problem of copyright can be solved. What is clear in all scenarios however, is that far from becoming an absolescent class, the publisher as the selector and processor will play a role of increasing importance in the future.
A persuasive argument for much greater cooperation among European publishers in the marketing of their journals outside Europe was put by M. Clarke of the UK Institute of Physics. Modern technology and budget limitations were depressing the market for primary productions and it was essential to develop markets outside, notably in the far East and S. America. Within Europe and the USA, communication was relatively easy and competitive marketing effective, but in distant countries, cooperation was necessary if European source material was to be known and accepted. There was considerable scope for the smaller publishers at the very least to share circulation lists, mailing costs, brochures, agencies and to make a joint presence at conferences and exhibitions. There was also scope for cooperation on distribution to cut not only direct costs, but the indirect costs including losses.

Much interest was expressed in the UNESCO coupon scheme which allows people to pay in their own currency for purchases made in hard currency areas. Of the 150 states belonging to UNESCO less than $1 / 3$ operate such a scheme and UNESCO has no control over the internal management. Nevertheless here was an area where something more might be done and there were indications that cooperation between publishers may not be an impossible goal.

Finally the Chairman of the Publications Committee, G. Eilenberger reviewed some of the areas where international organisations could play a useful part - recalling that apart from UNESCO and EPS there were umbrella organisations like IUPAP, international laboratories such as CERN and the professional and trade organisations such as the International Federation of Library Associations. Issues included the subjects already discussed, leading on to journal amalgamations and the information explosion (which one publisher was quick to point out was fuelled by the physicist).

Even if no immediate decisions were taken in Paris on who should do what, there were grounds for believing at the end of the day, that the different parties involv- ed in publishing are moving closer together and that all were anxious to speed the flow of information and reduce its cost. Proceedings of the meeting are in preparation.

\section{Plasma Physics}

The new Chairman of the Plasma Physics Division in place of F. Engelmann is:

A. Gibson

JET Joint Undertaking

Abingdon, England

\section{CMD General Conference}

The Second General Conference of the Condensed Matter Division is due to be held next month in Manchester (UK) 22-25 March, 1982. Chairman of the Conference is Prof. V. Heine (Cambridge). The Conference is a continuation of the general CMD conferences started in 1980 in Antwerp. Whereas previous meetings of the Condensed Matter Division were centred around one specific topic in condensed matter physics (as in Leeds in 1977) this series of conferences is designed to create an international forum where scientists active in all fields of condensed matter physics can meet and exchange their ideas and report on their findings and recent progress. In order to achieve this, the Programme Committee has selected about 60 invited speakers, many grouped in symposia, who will cover the whole spectrum. Several plenary talks are also included in the programme. Among the speakers are a Noble Prize laureate and the winner of the 1982 Hewlett-Packard Europhysics Prize. There will be parallel sessions for the contributed papers. Also two satellite meetings will follow the General Conference.

A general meeting for all members of the Division is scheduled for Monday evening. All members of the Division and participants in the Conference are cordially invited. It provides the opportunity to exchange views on the Division, its present status and future development.

Looking forward to seeing you in Manchester.

\section{J.T. Devreese, Chairman}

EPS Divisions, Sections and Group
Astronomy and Astrophysics Division
Solar Section
Atomic Physics Division
Atomic Spectroscopy Section
Chemical Physics
Electronic and Atomic Collisions
Molecular Physics
Computational Physics Group
Condensed Matter Division
Low Temperature Section
Macromolecular Physics
Magnetism
Metals
Semiconductors and Insulators
Surface and Interface
High Energy \& Particle Physics Division
Nuclear Physics Division
Plasma Physics Division
Quantum Electronics Division

EPS Divisions, Sections and Group

Astronomy and Astrophysics Division

Scopy Section

Chemical Physics

Electronic and Atomic Collisions

Low Temperature Section

Macromolecular Physics

Magnetis

Surface and Interface

Nuclear Physics Division

Quantum Electronics Division
Europhysics News is the official journal of the European Physical Society which comprises 28 National Socie ties, Academies and Groups, over 3000 Individual ties, Academies and Groups, over 3000 Individual dies of EPS are the General Meeting, Council and an elected Executive Committee responsible for detailed policy. EPS promotes the collaboration of physicists throughout Europe and encourages all aspects of international exchange in physics. EPS administers scholar ships awarded for research and studies in differen countries and a "teaching abroad" scheme. EPS publishes in addition to EN. Europhysics Conference Abstracts, E. Ed. News and, in collaboration with The Institute of Physics (UK), the European Journal of Physics. Individual Members receive EN free of charge (price to institutions: Sw.Fr. 82.-/a), rebates on the price of many publications and on conference fees. An nual subscription to EPS from Individual Members who belong to one of the EPS member societies is: SW.Fr 36. - ; for independent members: Sw.Fr. 126. -
Editor: E.N. Shaw

Meetings Compilation: W.S. Newman

Editorial Board:

K. Appert, A. Baratoff, G.J. Béné,

G.R. Macleod, A. Maeder, J. Muller

Editorial and Advertising Office at the EPS Secretariat.

Address: EUROPEAN PHYSICAL SOCIETY P.O. Box 69 CH-1213 Petit-Lancy 2 Switzerland

Telephone: Geneva (22) 931130

Telex: $23 \mathbf{4 5 5}$ alarm ch

Cables: europhys genève

Printed by: Pfirter frères SA

CH-1213 Petit-Lancy/Switzerland 